\title{
A shotgun antisense approach to the identification of novel essential genes in Pseudomonas aeruginosa
}

Ruggero Rusmini ${ }^{1 \dagger}$, Davide Vecchietti ${ }^{1 \dagger}$, Raffaella Macchi ${ }^{1}$, Faustino Vidal-Aroca ${ }^{1,2}$ and Giovanni Bertoni ${ }^{*}$

\begin{abstract}
Background: Antibiotics in current use target a surprisingly small number of cellular functions: cell wall, DNA, RNA, and protein biosynthesis. Targeting of novel essential pathways is expected to play an important role in the discovery of new antibacterial agents against bacterial pathogens, such as Pseudomonas aeruginosa, that are difficult to control because of their ability to develop resistance, often multiple, to all current classes of clinical antibiotics.
\end{abstract}

Results: We aimed to identify novel essential genes in P. aeruginosa by shotgun antisense screening. This technique was developed in Staphylococcus aureus and, following a period of limited success in Gram-negative bacteria, has recently been used effectively in Escherichia coli. To also target low expressed essential genes, we included some variant steps that were expected to overcome the non-stringent regulation of the promoter carried by the expression vector used for the shotgun antisense libraries. Our antisense screenings identified 33 growth-impairing single-locus genomic inserts that allowed us to generate a list of 28 "essential-for-growth" genes: five were "classical" essential genes involved in DNA replication, transcription, translation, and cell division; seven were already reported as essential in other bacteria; and 16 were "novel" essential genes with no homologs reported to have an essential role in other bacterial species. Interestingly, the essential genes in our panel were suggested to take part in a broader range of cellular functions than those currently targeted by extant antibiotics, namely protein secretion, biosynthesis of cofactors, prosthetic groups and carriers, energy metabolism, central intermediary metabolism, transport of small molecules, translation, post-translational modification, non-ribosomal peptide synthesis, lipopolysaccharide synthesis/modification, and transcription regulation. This study also identified 43 growth-impairing inserts carrying multiple loci targeting 105 genes, of which 25 have homologs reported as essential in other bacteria. Finally, four multigenic growth-impairing inserts belonged to operons that have never been reported to play an essential role.

Conclusions: For the first time in P. aeruginosa, we applied regulated antisense RNA expression and showed the feasibility of this technology for the identification of novel essential genes.

\section{Background}

Pseudomonas aeruginosa is a highly adaptable bacterium that thrives in a broad range of ecological niches. In addition, it can infect hosts as diverse as plants, nematodes, and mammals. In humans, it is an important opportunistic pathogen in compromised individuals,

\footnotetext{
* Correspondence: giovanni.bertoni@unimi.it

${ }^{\dagger}$ Equal contributors

'Department of Life Sciences, Università degli Studi di Milano, via Celoria 26, 20133 Milan, Italy

Full list of author information is available at the end of the article
}

such as patients with cystic fibrosis, severe burns, or impaired immunity $[1,2]$. P. aeruginosa is difficult to control because of its ability to develop resistance, often multiple, to all current classes of clinical antibiotics [3-5]. The discovery of novel essential genes or pathways that have not yet been targeted by clinical antibiotics can underlie the development of alternative effective antibacterials to overcome existing mechanisms of resistance. Whole-genome transposon-mutagenesis (TM) followed by identification of insertion sites is one of the most practical and frequently used experimental approaches to screen for

\section{Biomed Central}


essential bacterial genes [6-8]. Genome-wide surveys of essential genes in $P$. aeruginosa have been accomplished by saturating TM through a "negative" approach $[9,10]$, specifically, by identifying non-essential genomic regions by transposon insertion and deducing that non-inserted genome stretches are essential. However, this approach can suffer from some systematic biases that generate both false positives and negatives [7]. For example, even if comprehensive insertion libraries are produced, it is inevitable that some genes, especially the shortest ones, could elude insertion and be spuriously annotated as essential, while transposon insertions that occur at gene ends and do not fully inactivate the function could lead to genes being incorrectly classified as non-essential. To filter errors resulting from these intrinsic biases in the "negative" TM approach, a statistical framework has recently been developed and tested in $P$. aeuginosa PAO1 and Francisella tularensis novicida [7] TM datasets. Some drawbacks of the "negative" TM approach were overcome by using growth-conditional TM, which allows identification of essential genes by transcriptionally fusing them to an outward-facing inducible promoter located at one end of the transposon [11]. However, conditional TM can also be affected by systematic biases, deriving, for example, from transposon tools endowed with outward-facing promoters that are not strictly regulated in non-inducing conditions, resulting in a basal level of promoter expression. In fact, promoter leakage under non-inducing conditions would not completely switch off the gene downstream of the insertion site, significantly increasing the false-negative identification rate. The TM tools applicable for use with $P$. aeruginosa [12] are based on elements used for tightly regulated gene expression in E. coli, and are expected to not be completely switched off in non-inducing conditions when used "out-of-context". For these reasons, we set out to screen novel essential genes of $P$. aeruginosa using a method other than TM. To this end, we selected shotgun antisense RNA identification of essential genes, a technique that was developed a decade ago in Staphylococcus aureus $[13,14]$. This technique originally only showed limited success in Gram-negative bacteria $[15,16]$, but has recently been used effectively in E. coli [17]. In this approach, essential genes are identified after shotgun-cloned genomic fragments are conditionally expressed. The fragments are screened to identify those whose expression impairs growth [18]. The genes targeted by antisense RNA are identified by DNA sequencing of the growth-impairing fragments. This study shows for the first time the feasibility of the antisense technology in P. aeruginosa for identifying novel essential genes. Moreover, we included some modifications to the original strategy that could have broadened the functional class variety of the identified essential genes in respect to a recent report in E. coli [17].

\section{Results}

Ad hoc procedure to screen for essential $P$. aeruginosa genes by antisense RNA effects

According to the scheme for antisense-mediated identification of essential genes established in $S$. aureus $[13,14]$, the shotgun genomic libraries generated in vitro are directly introduced into the original host by transformation, and selected in permissive conditions, i.e., with the promoter vector in an off state, to allow the clones carrying inserts targeting essential genes to survive. However, basal vector promoter activity could be sufficient to elicit silencing effects against genes transcribed at low levels. This effect may introduce a bias in the subsequent conditional screening, favoring the identification of highly transcribed essential genes (e.g., tRNAs, tRNA synthetases, ribosomal proteins, translation factors, components of the transcription machinery). Cells transformed using constructs targeting essential genes expressed at low levels will fail to form a colony in the permissive conditions. The high basal $P_{t r c}$ activity was suggested to cause the identification of a relevant proportion of highly expressed essential genes in a recent antisense screening of $E$. coli [17]. A not entirely negligible basal activity is frequent in the commonly used expression system tools, especially when they are used outside the source organism. This is the case in the $P_{B A D}$ promoter-based systems, like those selected for this study, which have been used for tightly regulated gene expression in $E$. coli, and for efficient arabinose-induced overexpression in other hosts. However, outside of the E. coli regulatory context, for instance in Burkholderia pseudomallei [19] and P. aeruginosa (Bertoni et al., unpublished), these systems can display, also in the presence of glucose, a basal level of activity. To avoid missing the identification of low expressed essential genes owing to out-of-context use of the $P_{B A D}$ promoter, we set out to generate $P$. aeruginosa genomic shotgun libraries in E. coli first, and to then array and challenge them by conjugative transfer into $P$. aeruginosa (Figure 1). Moreover, this strategy assures a larger sized shotgun library because of the higher transformation efficiency of $E$. coli compared with $P$. aeruginosa. To test the robustness of this approach, we checked the false-positive rate due to failure of vector mating transfer and assessed that it was negligible.

\section{Construction of arrayed shotgun genomic libraries of P. aeruginosa}

Genomic DNA was purified from $P$. aeruginosa PAO1 and then mechanically sheared to generate DNA fragments in a size range spanning 200-800 bp (Additional file 1: Figure S1A). In pilot experiments, 


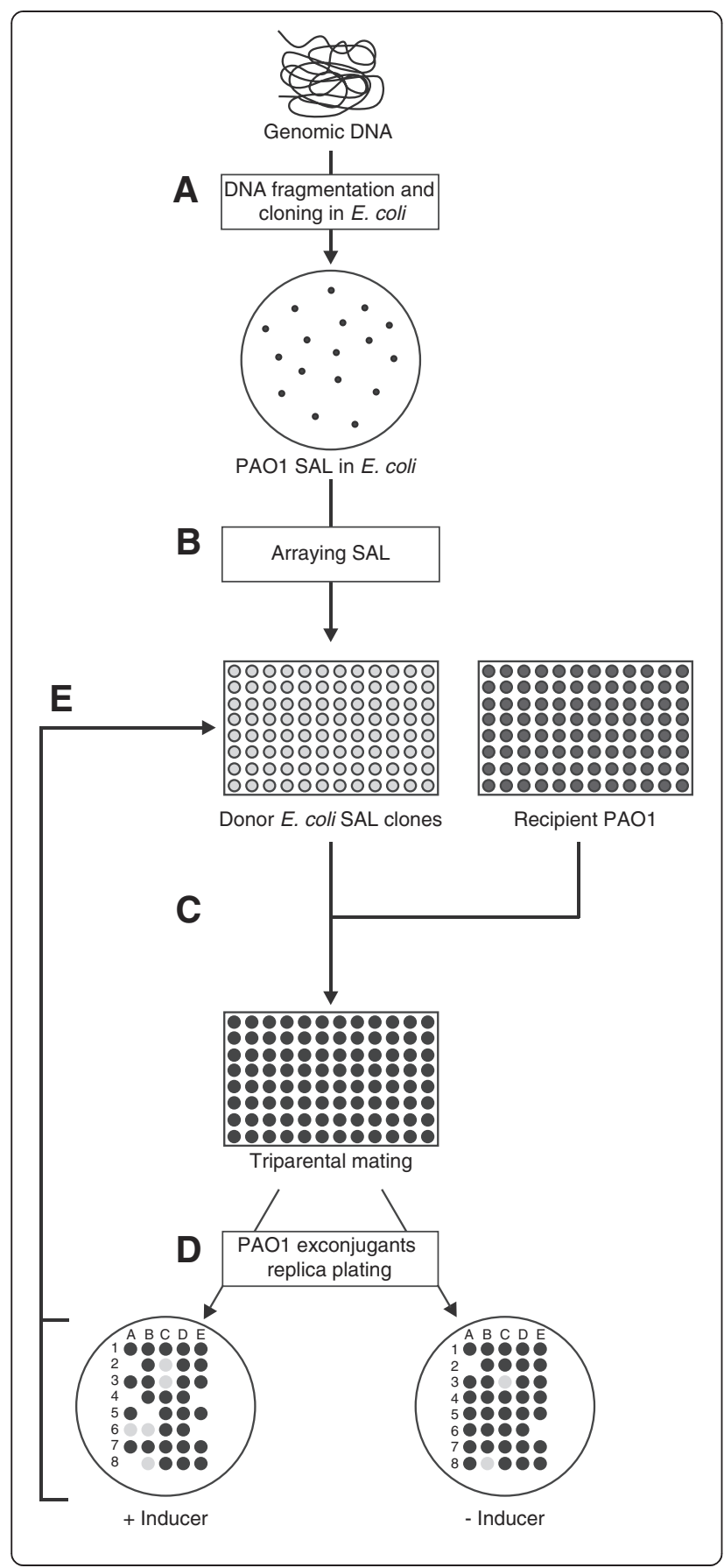

Figure 1 Construction and screening of PAO1 SALs. (A) Genomic DNA was isolated from $P$. aeruginosa PAO1 and nebulized to obtain sheared fragments of 200-800 bp. After treatment with exonuclease BAL-31 and Klenow polymerase, the genomic DNA fragments were cloned into the E. coli strain JM109, downstream of the arabinose-inducible promoter $\mathrm{P}_{\mathrm{BAD}}$ of the PHERD20T vector. (B) E. coli transformants, representing the PAO1 shotgun antisense library (SAL), were arrayed in 96-well microplates and (C) mated with $P$. aeruginosa $\mathrm{PAO} 1$ in the presence of a helper strain (triparental mating). (D) SAL recipient PAO1 exconjugants were selected by spotting on PIA plates supplemented with $\mathrm{Cb}$ both in the absence and in the presence of the $\mathrm{P}_{\mathrm{BAD}}$ inducer arabinose. Recipient PAO1 exconjugant spots were inspected for growth defects following $24 \mathrm{~h}$ of incubation at $37^{\circ} \mathrm{C}$. (E) The identity of the genomic fragments eliciting growth defects (lethal effects, indicated by a lack of a spot: only with inducer, e.g. clones $A 4, A 8, B 5$, and $E 4$, and with and without an inducer, e.g. clones A2 and E6; growth impairment, indicated as gray spots: only with an inducer, e.g. clones $C 2, A 6$, and $B 6$, and with and without an inducer, e.g. C3 and B8) was determined by sequencing the inserts in the corresponding clones of E. coli SAL.

following treatment with exonuclease BAL-31 and Klenow polymerase, the $200-800 \mathrm{bp}$ DNA fragments were cloned into $E$. coli downstream of the arabinose-inducible promoter, $P_{B A D}$, of the broad host-range vector pVI533EH. Approximately 800 transformant clones were then arrayed in 96-well microplates. Analysis of cloning efficiency by PCR indicated that about $30 \%$ of transformant E. coli colonies carried a PAO1 genomic insert. To generate shotgun antisense libraries (SALs) with a lower background of clones carrying an empty vector, we selected the broad host-range vector pHERD-20 T, which facilitates the identification of clones carrying an insert based on blue/white screening. We obtained a 7:3 ratio between dark blue (absence of an insert) and white-light blue (potential presence of an insert) colonies, with 95\% of white-light blue colonies carrying an insert with the expected average size (Additional file 1: Figure S1B). Thus, the probability of selecting a clone with an insert (Additional file 1: Figure S1C) increased from about 30\% to 95\% using pHERD-20 T. A pHERD-20 T-based SAL library was constructed by arraying approximately 10,000 white-light blue transformant clones in 96-well microplates.

\section{Screenings of SALs for growth-impairing inserts}

The genomic inserts of both pVI533EH- and pHERD20 T-based SALs were screened for their ability to impair PAO1 growth, supposedly by antisense transcription effects, by mating transfer of SALs from E. coli to PAO1 (Figure $1 C$ ), and then replica plating of exconjugants on Pseudomonas Isolation Agar (PIA) supplemented with carbenicillin $(\mathrm{Cb})$, both in the absence and presence of the $P_{B A D}$ inducer arabinose (Figure 1D). Recipient PAO1 exconjugant spots were inspected for growth defects following $24 \mathrm{~h}$ of incubation at $37^{\circ} \mathrm{C}$. Insert-induced 
impairment ranged from growth defect to arrest, which could be displayed in some cases even in the absence of arabinose (Additional file 1: Figure S1C). This suggested that basal insert expression in PAO1, a regulatory context for $P_{B A D}$ that is not as restrictive as $E$. coli, was sufficient to produce deleterious effects on growth. These screenings resulted in the identification of five and 71 growth-impairing inserts in the pVI533EH- and pHERD-20 T-based SALs, respectively. These 76 inserts, recovered in the corresponding E. coli donor clones (Figure 1E), were subjected to sequence analysis, and their features are listed in Additional file 2: Table S2.

\section{Analysis of the growth-impairing inserts}

Bioinformatic analysis of the DNA sequences obtained indicated that 33 of the 76 positive clones $(44 \%)$ contained single intragenic fragments. Of these, 20 (26\% of the positive clones) were in antisense orientation. As listed in Table 1, some of these fragments derived from conserved genes involved in DNA replication, transcription, and translation, such as $d n a G, r p o C, r p o B$, $\inf B$, and $r b f A$, which can be considered "classical" essential genes. Fragments derived from rpoC, rpoB, infB, and $r b f A$ were antisense oriented. Two different fragments were derived from $d n a G$, one antisense and the other sense oriented. As previously suggested [13], it is likely that sense-oriented intragenic fragments can act as dominantnegative interfering sequences. Alternatively, we suggest that transcription noise in the vector backbone from the other side of $P_{B A D}$ could produce sufficient amounts of insert antisense transcripts to silence the target essential gene. One insert targeted PA3820 ( $\sec F)$, which was previously shown to play an essential role in several bacterial species [20]. Six intragenic fragments derived from PA4669 (ipk), PA2951 (etfA), PA3687 (ppc), PA3758 (nagA), PA1183 (dctA), and PA1805 (ppiD), which are homologous to genes previously shown to be essential in a limited number of bacterial species [20].

The other inserts shown in Table 1 are derived from 16 genes with no homologs annotated as essential [20]. We recently validated the essential role of one of these hits, TgpA (PA2873), in P. aeruginosa by insertional and conditional mutagenesis [21]. In addition, the critical role of PA1554 (ccoN1) in the aerobic growth of $P$. aeruginosa PAO1 was reported previously [22].

The remaining positive clones contained fragments including multiple loci and targeted a total of 103 genes (Additional file 3: Table S3). Nineteen of these multigenic fragments included 25 genes with homologs described as essential in other bacterial species [20]. The rest of the multigenic fragments carried genes with no evidence of an essential role. Interestingly, four multigenic inserts included gene sequences belonging to a single operon (Table 2).

\section{Discussion}

The discovery of novel essential genes or pathways that have not yet been targeted by clinical antibiotics can underlie the development of alternative effective antibacterials to overcome the extant mechanisms of resistance. In $P$. aeruginosa, a genome-wide assessment of essential genes has been performed previously by constructing an ordered, nonredundant random transposon ( $\mathrm{Tn}$ ) insertion library $[9,10,23]$. An approach of this kind has proven invaluable in studying bacterial genomes and in detecting novel essential genes. However, there can be some degree of imprecision in tagging for essentiality owing to $\mathrm{Tn}$ insertions into possible permissive site(s) of essential genes. For example, "classical" essential genes involved in DNA replication, transcription, translation, and cell division (e.g. polA, holE, holB, holC, dnaG, dnaJ, dnaK, rpoC, infC, and ftsYEX) were Tn inserted in previous investigations (Additional file 4: Table S4) $[9,10,23]$ and, for this reason, $P$. aeruginosa alleles were not included in the Database of Essential Genes (DEG) [20]. Some disadvantages of this kind of approach could be overcome by using growth-conditional mutagenesis.

To generate growth-conditional phenotypes, we decided to use the antisense-mediated strategy established previously in S. aureus [13,14]. This technique is not affected by some of the bias linked to transposon mutagenesis mentioned above. However, it can present limitations in the multi-step process of antisense libraries preparation such as the blunt-end cloning of mechanically sheared DNA fragments, library clones carrying multigenic inserts, the reintroduction efficiency of libraries into the original host. In addition, the efficiency of antisense inhibition, supposed to affect gene translatability and/or mRNA stability, can be gene-dependent and also differential for distinct DNA fragments belonging to the same gene.

We report here, for the first time, successful application of regulated antisense RNA technology to discover novel essential functions in $P$. aeruginosa. To also screen for low expressed essential genes, we added a preliminary shotgun library construction in E. coli to the previous strategy, followed by mating transfer to $P$. aeruginosa.

The subset of growth-impairing fragments that targeted single loci (Table 1) directly defined 28 "essential-for-growth" genes. Only five of these genes were "classical" essential genes involved in DNA replication, transcription, and translation. The remaining 23 genes are suggested to take part in disparate cellular functions, including protein secretion, biosynthesis of cofactors, prosthetic groups, and carriers, energy metabolism, central intermediary metabolism, transport of small molecules, translation, post-translational modification, non-ribosomal peptide synthesis, lipopolysaccharide synthesis/modification, and transcriptional regulation. Finally, some of the gene products described in Table 1 were annotated as "hypothetical" 
Table 1 Pseudomonas aeruginosa PAO1 genes targeted by growth-impairing inserts including a single locus

\begin{tabular}{|c|c|c|c|c|}
\hline $\begin{array}{l}\text { Insert } \\
\text { name }^{a}\end{array}$ & $\begin{array}{l}\text { Insert-included } \\
\text { locus }\end{array}$ & Gene name and product annotation ${ }^{b}$ & Function class $^{b}$ & $\begin{array}{l}\text { Orthologous proteins in } \\
\text { DEG }^{c}\end{array}$ \\
\hline S2F1 & \multirow[t]{2}{*}{ PA0577 } & \multirow[t]{2}{*}{ dnaG - DNA primase (2) } & \multirow{2}{*}{$\begin{array}{l}\text { DNA replication, recombination, } \\
\text { modification and repair }\end{array}$} & \multirow{2}{*}{$\begin{array}{l}\mathrm{Bs}, \mathrm{Sa}, \mathrm{Ec}, \mathrm{Hi}, \mathrm{Sp}, \mathrm{Mt}, \mathrm{Fn}, \\
\mathrm{Ab}, \mathrm{Mp}, \mathrm{Se}, \mathrm{Cc}, \mathrm{Ss}\end{array}$} \\
\hline S3D3 & & & & \\
\hline S11F7 & PA4269 & $\begin{array}{l}\text { rpoC - DNA-directed RNA } \\
\text { polymerase beta chain ( } 2 \text { ) }\end{array}$ & $\begin{array}{l}\text { Transcription, RNA processing } \\
\text { and degradation }\end{array}$ & $\begin{array}{l}\text { Bs, Sa, Ec, Mg, Sp, Mt, St, } \\
\mathrm{Fn}, \mathrm{Ab}, \mathrm{Mp}, \mathrm{Se}, \mathrm{Ss}, \mathrm{Pg}\end{array}$ \\
\hline B1 & PA4270 & $\begin{array}{l}\text { rpoB - DNA-directed RNA } \\
\text { polymerase beta chain (2) }\end{array}$ & $\begin{array}{l}\text { Transcription, RNA processing } \\
\text { and degradation }\end{array}$ & $\begin{array}{l}\mathrm{Bs}, \mathrm{Sa}, \mathrm{Vc}, \mathrm{Ec}, \mathrm{Hi}, \mathrm{Mg}, \mathrm{Mt}, \mathrm{St} \\
\mathrm{Fn}, \mathrm{Ab}, \mathrm{Mp}, \mathrm{Pa}, \mathrm{Se}, \mathrm{Cc}, \mathrm{Ss}, \mathrm{Pg}, \mathrm{Bt}\end{array}$ \\
\hline S6A10 & PA4744 & $\begin{array}{l}\text { infB - translation initiation } \\
\text { factor IF-2 (2) }\end{array}$ & $\begin{array}{l}\text { Translation, post-translational } \\
\text { modification, degradation }\end{array}$ & $\begin{array}{l}\mathrm{Bs}, \mathrm{Sa}, \mathrm{Vc}, \mathrm{Ec}, \mathrm{Mg}, \mathrm{Mt}, \mathrm{St} \\
\mathrm{Fn} \mathrm{Ab}, \mathrm{Mp}, \mathrm{Pa}, \mathrm{Se}, \mathrm{Cc}, \mathrm{Pg}, \mathrm{Bt}\end{array}$ \\
\hline S2F6 & PA4743 & rbfA - ribosome-binding factor A (2) & $\begin{array}{l}\text { Translation, post-translational } \\
\text { modification, degradation }\end{array}$ & $\mathrm{Sa}, \mathrm{Vc}, \mathrm{Mg}, \mathrm{Hp}, \mathrm{Fn}, \mathrm{Ab}, \mathrm{Se}$ \\
\hline S6E7 & PA3820 & secF - secretion protein SecF (2) & Protein secretion/export apparatus & $\mathrm{Ec}, \mathrm{Hi}, \mathrm{St}, \mathrm{Fn}, \mathrm{Ab}, \mathrm{Pa}$, Se \\
\hline S5A10 & PA1709 ${ }^{d}$ & $\begin{array}{l}\text { popD - Translocator outer } \\
\text { membrane protein (1) }\end{array}$ & Protein secretion/export apparatus & \\
\hline S11B13 & PA4669 & $\begin{array}{l}\text { ipk - isopentenyl monophosphate } \\
\text { kinase(2) }\end{array}$ & $\begin{array}{l}\text { Biosynthesis of cofactors, prosthetic } \\
\text { groups and carriers }\end{array}$ & $\mathrm{Vc}, \mathrm{Se}, \mathrm{Pa}$ \\
\hline G2 & \multirow[t]{2}{*}{ PA2951 } & \multirow{2}{*}{$\begin{array}{l}\text { etfA - electron transfer flavoprotein } \\
\text { alpha-subunit (2) }\end{array}$} & \multirow[t]{2}{*}{ Energy metabolism } & \multirow[t]{4}{*}{$\mathrm{Ab}, \mathrm{Cc}$} \\
\hline $\mathrm{H} 2$ & & & & \\
\hline S10F8 & PA5186 & $\begin{array}{l}\text { probable iron-containing alcohol } \\
\text { dehydrogenase (3) }\end{array}$ & Energy metabolism & \\
\hline F1 & PA1554 & $\begin{array}{l}\text { ccoN } 1 \backslash \text { fix } \backslash \backslash \text { Cytochrome c oxidase, } \\
\text { cbb3-type, CcoN subunit (1) }\end{array}$ & Energy metabolism & \\
\hline S11G10 & PA3687 & ppc - phosphoenolpyruvate carboxylase (2) & Energy metabolism & $\mathrm{Hi}$ \\
\hline S86C & PA3758 & $\begin{array}{l}\text { nagA - probable N-acetylglucosamine-6-phosphate } \\
\text { deacetylase (3) }\end{array}$ & Central intermediary metabolism & $\mathrm{Hi}, \mathrm{Mt}$ \\
\hline E5 & PA1183 & $d c t A$ - C4-dicarboxylate transport protein (2) & Transport of small molecules & $\mathrm{Ab}$ \\
\hline S11C9 & PA3382 & phnE - phosphonate transport protein PhnE (2) & Transport of small molecules & \\
\hline S4E6 & PA4903 & $\begin{array}{l}\text { vanK - probable major facilitator superfamily } \\
\text { (MFS) transporter (3) }\end{array}$ & Transport of small molecules & \\
\hline B3 & \multirow[t]{2}{*}{ PA5548 } & \multirow{2}{*}{$\begin{array}{l}\text { probable major facilitator superfamily } \\
\text { (MFS) transporter (3) }\end{array}$} & \multirow[t]{2}{*}{ Transport of small molecules } & \\
\hline $\mathrm{S} 4 \mathrm{H} 12$ & & & & \\
\hline A5 & PA1590 & braB - branched chain amino acid transporter (1) & Transport of small molecules & \\
\hline S3D4 & PA1805 & $\begin{array}{l}\text { ppiD - peptidyl-prolyl cis-trans isomerase } \\
\text { D - Rotamase D (2) }\end{array}$ & $\begin{array}{l}\text { Translation, post-translational } \\
\text { modification, degradation }\end{array}$ & $\mathrm{Cc}, \mathrm{Bs}$ \\
\hline S9G5 & \multirow[t]{2}{*}{ PA2402 } & \multirow[t]{2}{*}{ Probable non-ribosomal peptide synthetase (3) } & \multirow[t]{2}{*}{ Putative enzymes } & \\
\hline S5D4 & & & & \\
\hline S5A4 & \multirow[t]{2}{*}{ PA5238 } & \multirow[t]{2}{*}{ probable O-antigen acetylase (3) } & \multirow{2}{*}{$\begin{array}{l}\text { Membrane proteins, } \\
\text { Cell wall/LPS/capsule }\end{array}$} & \\
\hline S5G6 & & & & \\
\hline S4B10 & PA3433 & ywbl - probable transcriptional regulator (3) & Transcriptional regulators & \\
\hline S5A1 & PA2220 & oprR - probable transcriptional regulator (3) & Transcriptional regulators & \\
\hline M4G6 & PA2873 & $\operatorname{tgp} A$ - transglutaminase protein A TgpA (1) & $\begin{array}{l}\text { Adaptation, Protection, } \\
\text { Membrane proteins }\end{array}$ & \\
\hline S10A3 & PA0307 & hypothetical protein (4) & $\begin{array}{l}\text { Hypothetical, unclassified, } \\
\text { unknown }\end{array}$ & \\
\hline
\end{tabular}


Table 1 Pseudomonas aeruginosa PAO1 genes targeted by growth-impairing inserts including a single locus (Continued)

\begin{tabular}{|c|c|c|c|}
\hline S841F & PA4926 & conserved hypothetical protein (4) & $\begin{array}{l}\text { Hypothetical, unclassified, } \\
\text { unknown }\end{array}$ \\
\hline S9A9 & PA0262 & conserved hypothetical protein (4) & $\begin{array}{l}\text { Hypothetical, unclassified, } \\
\text { unknown }\end{array}$ \\
\hline $\mathrm{F} 2$ & PA5264 & hypothetical protein (4) & $\begin{array}{l}\text { Hypothetical, unclassified, } \\
\text { unknown }\end{array}$ \\
\hline
\end{tabular}

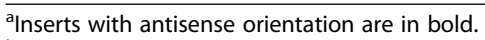

${ }^{\mathrm{b}}$ Annotations according to the Pseudomonas Genome Database (www.pseudomonas.com) [27]. Numbers inside parenthesis indicate the classes of product name confidence. Class1: Function experimentally demonstrated in P. aeruginosa; Class 2: Function of highly similar gene experimentally demonstrated in another organism; Class 3: Function proposed based on presence of conserved amino acid motif, structural feature or limited sequence similarity to an experimentally studied gene. Class 4: Homologs of previously reported genes of unknown function, or no similarity to any previously reported sequences.

'DEG: Database of Essential Genes (DEG 7.0) (www.essentialgene.org) [20]. For each hit, the orthologue proteins, extracted from the Ortholuge DB [30], that were found in DEG are indicated with the abbreviation of the harboring bacterial species. Bacterial species: Ab (Acinetobacter baylyi), Bs (Bacillus subtilis), Bt (Bacteroides thetaiotaomicron), Cc (Caulobacter crescentus), Ec (Escherichia coli), Fn (Francisella novicida), Hi (Haemophilus influenzae), Hp (Helicobacter pylori), Mt (Mycobacterium tuberculosis), Mp (Mycoplasma pulmonis), Mg (Mycoplasma genitalium), Pg (Porphyromonas gingivalis), Pa (Pseudomonas aeruginosa), Se (Salmonella enterica), St (Salmonella typhimurium), Sp (Streptococcus pneumoniae), Ss (Streptococcus sanguinis), Sa (Staphylococcus aureus), Vc (Vibrio cholerae).

${ }^{\mathrm{d}}$ Previous reports [24-26] did not mention growth defects associated to deletion of popD gene.

${ }^{{ }^{H}}$ Hit not present in DEG whose essentiality was experimentally demonstrated in $P$. aeruginosa [21].

proteins. We suggest that these proteins may be involved in unexplored essential functions, either as stand-alone proteins or connected to classical housekeeping processes. This is the case for the inner membrane protein TgpA (PA2873; Table 1) [21], which was found in our antisense screenings and was previously reported as hypothetical, whose transglutaminase activity associated with the periplasmic domain might be either linked to cell wall metabolism or be involved in unknown key functions of protein maturation, secretion, and/or modification.

Only two of the 23 non-classical essential genes, PA4669 (ipk) and PA3820 (secF), were already indicated as essential in $P$. aeruginosa $[9,20]$. For the remaining 21 genes, no evidence for essentiality has been reported previously in $P$. aeruginosa [20]. We propose these genes as novel essential genes in P. aeruginosa. PA2951 (etfA), PA3687 (ppc), PA3758 (nagA), PA1183 (dctA), and PA1805 (ppiD) are homologous to genes previously shown to be essential in a limited number of bacterial species [20]. Interestingly, for the remaining 16 genes, no homologs have been reported as essential in other bacteria [20]. Among these, PA1709 (popD), coding for a subunit of the PopB/D translocon complex of the type III secretion-translocation system (TTSS), is implicated in effector translocation across the host plasma membrane.

Table 2 PAO1 growth-impairing inserts including loci belonging to a single operon

\begin{tabular}{|c|c|c|c|c|}
\hline $\begin{array}{l}\text { Insert } \\
\text { name }^{a}\end{array}$ & Operon locib & Gene name and product annotation ${ }^{c}$ & Function class $^{c}$ & $\begin{array}{l}\text { Species containing } \\
\text { orthologs in } \mathrm{DEG}^{\mathrm{d}}\end{array}$ \\
\hline \multirow[t]{4}{*}{ E6 } & PA1037 & yicG - conserved hypothetical protein (4) & \multirow[t]{4}{*}{ Hypothetical, unclassified, unknown } & \\
\hline & PA1038 & hypothetical protein (4) & & \\
\hline & PA1039 & ychJ - hypotetical protein (4) & & \\
\hline & PA1040 & hypothetical protein (4) & & \\
\hline \multirow[t]{3}{*}{ S9B6a } & PA1089 & conserved hypothetical protein (4) & \multirow[t]{3}{*}{ Hypothetical, unclassified, unknown } & \\
\hline & PA1090 & conserved hypothetical protein (4) & & \\
\hline & PA1088 & hypothetical protein (4) & & \\
\hline \multirow[t]{3}{*}{ S9B6b } & PA0393 & proC - pyrroline-5-carboxylate reductase (1) & Amino acid biosynthesis and metabolism & E. coli, M. tuberculosis, A. baylyi \\
\hline & PA0392 & yggT - conserved hypothetical protein (4) & \multirow[t]{2}{*}{ Hypothetical, unclassified, unknown } & \\
\hline & PA0394 & yggs - conserved hypothetical protein (4) & & \\
\hline \multirow[t]{2}{*}{$\mathrm{S} 2 \mathrm{~A} 4$} & PA1001 & phnA - anthranilate synthase component I (1) & \multirow{2}{*}{$\begin{array}{l}\text { Adaptation, protection; amino acid } \\
\text { biosynthesis }\end{array}$} & \\
\hline & $\mathrm{PA} 1002^{\mathrm{e}}$ & phnB - anthranilate synthase component II (1) & & \\
\hline
\end{tabular}

${ }^{a}$ Inserts with antisense orientation are in bold.

${ }^{b}$ Loci included in the insert are in bold.

'Annotations according to the Pseudomonas Genome Database (www.pseudomonas.com) [27]. Numbers inside parenthesis indicate the classes of product name confidence. Class1: Function experimentally demonstrated in P. aeruginosa; Class 2: Function of highly similar gene experimentally demonstrated in another organism; Class 3: Function proposed based on presence of conserved amino acid motif, structural feature or limited sequence similarity to an experimentally studied gene. Class 4: Homologs of previously reported genes of unknown function, or no similarity to any previously reported sequences.

${ }^{\mathrm{d} D E G: ~ D a t a b a s e ~ o f ~ E s s e n t i a l ~ G e n e s ~(D E G ~ 7.0) ~(w w w . e s s e n t i a l g e n e . o r g) ~[20] . ~}$

ePrevious reports $[34,35]$ did not mention growth defects associated to deletion of phnAB genes. 
Previous reports on $P$. aeruginosa PopD function [24-26] did not mention growth defects associated to deletion of popD gene. Therefore, the growth-impairing effects of S5A10 insert corresponding to PA1709 (Table 1) did not seem to match the PopD role characterized so far. These discrepancies could be due to differences in experimental conditions between our study and earlier works.

We evaluated the set of 21 novel candidate essential genes for degree of conservation in Pseudomonas species according to the computationally-based analysis of orthologs of the Pseudomonas Genome Database [27] (Additional file 5: Table S5). Interestingly, they are well-conserved in the sequenced Pseudomonas species, with the exceptions of PA5548 and PA1709 (popD) that are unique in P. aeruginosa. However, PA5548 and PA1709 (popD) orthologs can be found in other bacterial species. Remarkably, 17 of 21 novel essential candidates are conserved in all twelve sequenced $P$. aeruginosa genomes (Additional file 5: Table S5). Instead, PA2220 (oprR), PA5264, PA1709 (popD) and PA3687 (ppc) are present in $3,8,9$ and 10 of the sequenced genomes, respectively. Essential genes that are not fully conserved in all strains of a bacterial species can occur infrequently. As an example, the Escherichia coli genes $y t f I, y p j F$, $y m f J$, $y m f I$ and $y m c D$, coding for hypothetical proteins, were reported as essential in the K12-MG1655 strain $[28,29]$ and are conserved in only a limited number of the sequenced E. coli genomes [30].

Moreover, we compared the novel essential candidates with a panel of "classical" essential genes that were not included in the Database of Essential Genes (DEG) [20] because of the occurence of Tn insertions in previous screenings in $P$. aeruginosa $[9,10,23]$. The Tn insertion patterns of the novel essential candidates (i.e. number of insertions and insertion site(s)- terminal $v s$ internal; Additional file 5: Table S5) were similar to those of "classical" essential genes (Additional file 4: Table S4).

This study also identified growth-impairing inserts carrying multiple genes. Because of their multigenic composition, the tagging of genes in these constructs for essentiality is not as direct as for single locus inserts (see above). However, among the multigenic inserts, we identified sequences corresponding to 25 genes with homologs already annotated as essential in other bacterial species [20] (Additional file 3: Table S3). Seven of these genes were indicated previously as essential in $P$. aeruginosa $[9,20]$. The 25 genes were annotated as involved in multiple cellular functions: lipid A biosynthesis $(\operatorname{lp} x A, \operatorname{lp} x B ; \operatorname{lp} x D, f a b Z)[31]$, amino acid biosynthesis and metabolism (glyA3, proC, hom, lys $C$, ldh), DNA replication and recombination (dnaX, recB, recR), transport of small molecules (potD, $m g t A, f a d L$, fepG, pstC), biosynthesis of cofactors, prosthetic groups and carriers $(f o l D)$, translation and post-translational modification
(tufB), nucleotide biosynthesis (purL), protein secretion $(\sec E)$, tRNA modification $(g c p)$ [32], central intermediary metabolism $(g l p K)$, and energy metabolism $(f d x 2)$. Other genes present in the multigenic inserts might be essential, but their identification would require further analysis via subcloning and/or conditional mutagenesis.

Interestingly, four multigenic inserts contained genes belonging to a single operon (Table 2), a feature that suggests a functional association. One such gene, proC, codes for pyrroline-5-carboxylate reductase [33] and was reported as essential in E. coli, Mycobacterium tuberculosis and Acinetobacter baylyi [20]. Other gene products of these operons are annotated as hypothetical proteins. Therefore, we suggest that these operonic genes might be involved in novel essential pathways. Overall, they are well-conserved in the sequenced Pseudomonas species (Additional file 5: Table S5). Exceptions are PA1088-1089-1090 which appear restricted to few Pseudomonas species and not conserved in all sequenced $P$. aeruginosa strains. Finally, one operonic growth-impairing insert included PA1001-1002 (phnAB) implicated in the biosynthesis of pyocyanin. Previous reports on $P$. aeruginosa PAO1 phnA and PA14 phnAB function $[34,35]$ did not mention growth defects associated to deletion of these genes. As in the case of PA1709 (popD), discrepancies between our results and previous works could be attributable to differences in experimental conditions.

\section{Conclusions}

Taken together, our results show the feasibility of antisense technology in $P$. aeruginosa for identifying novel essential genes. Because of its supposed inefficiency [16], this approach has been neglected in Gram-negative bacteria for several years, and was only recently recovered in $E$. coli [17]. By comparison with this previous work, the results presented here strongly suggest that our modification of the antisense strategy could broaden the class variety of the identified essential genes. We expect that our methodology could be well suited for antisense-mediated searches of essential genes in other Gram-negative bacterial species.

\section{Methods}

\section{Bacterial strains, plasmids, and growth conditions}

Bacterial strains and plasmids used in this study are listed in Additional file 6: Table S1. Bacteria were grown at $37^{\circ} \mathrm{C}$ in Luria-Bertani (LB) broth, or in M9 minimal medium supplemented with $0.2 \%$ citrate (M9-citrate). Antibiotics were added at the following concentrations $(\mu \mathrm{g} / \mathrm{ml}): \mathrm{Cb}, 300$; kanamycin; 50 . Arabinose was added to a final concentration of $10 \mathrm{mM}$. In mating experiments, exconjugant $P$. aeruginosa PAO1 clones were selected on PIA (Difco) containing $\mathrm{Cb}$. 


\section{Construction and screening of PAO1 shotgun antisense libraries}

Genomic DNA was isolated from $P$. aeruginosa PAO1 using an illustra GenomicPrep Cells and Tissue DNA Isolation Kit (GE Healthcare). DNA was diluted in $10 \mathrm{mM}$ TE buffer ( $\mathrm{pH}$ 8.0) and nebulized to obtain sheared fragments spanning 200-800 bp (Additional file 1: Figure S1A). Following ethanol precipitation, fragmented DNA was treated with nuclease BAL-31 and Klenow (New England Biolabs) for $10 \mathrm{~min}$ at $30^{\circ} \mathrm{C}$ to obtain blunt ends. After enzyme inactivation with $1 \mathrm{mM}$ EDTA, DNA was dialyzed against $20 \mathrm{mM}$ Tris- $\mathrm{HCl}$ (pH 8.0). pVI533EH and pHERD20T were digested with SmaI (New England Biolabs) and dephosphorylated using shrimp alkaline phosphatase (Roche). Fragmented DNA was ligated to dephosphorylated vectors using T4 Ligase (Takara Bio) at $16^{\circ} \mathrm{C}$ overnight. Ligation mixtures were transformed into E. coli JM109 by electroporation, and transformants were selected on LB plates supplemented with $\mathrm{Cb}$. The resulting transformant colonies composing the SAL were arrayed and cultured in 96-well microplates. Quality control by PCR of single colonies, using primers flanking the multi-cloning site (Additional file 1: Figure S1B), was performed to check the presence and the size of a genomic insert.

SALs were mobilized from $E$. coli to $P$. aeruginosa PAO1 by conjugative triparental mating. $E$. coli donor strains were grown overnight in 96-well microplates in LB broth supplemented with $\mathrm{Cb}$. The recipient $P$. aeruginosa PAO1 and helper E. coli HB101/pRK2013 strains were grown overnight in flasks in LB broth. Thirty microliters each of helper, recipient, and donor strains were mixed in microplate wells. After mixing, microplates were centrifuged at $750 \times \mathrm{g}$ for $5 \mathrm{~min}$ and incubated for $3 \mathrm{~h}$ at $37^{\circ} \mathrm{C}$. Cell pellets resulting from triparental mating were resuspended in $90 \mu \mathrm{l}$ of $\mathrm{LB}$, and $2 \mu \mathrm{l}$ of each mating mixture were spotted on PIA plates supplemented with $\mathrm{Cb}$, both in the absence and presence of $10 \mathrm{mM}$ arabinose, to counter select $E$. coli donor and helper strains. Exconjugant cell spots were inspected for growth defects following 24-48 h of incubation at $37^{\circ} \mathrm{C}$. The PAO1 growth-impairing inserts in pVI533EH/pHERD20T derivatives were sequenced following PCR amplification using oligo pVI533-F/pVI533-R and pHERD-F/pHERD-R, respectively (Additional file 6: Table $\mathrm{S} 1$ ). The resulting sequences were matched to the PAO1 genome at the Pseudomonas Genome Database [27].

\section{Additional files}

Additional file 1: Figure S1. Construction and screening for growth defects of $P$. aeruginosa shotgun antisense libraries. A. Agarose gel electrophoresis showing two fractions, F1 and F2 (lanes 2 and 3), of DNA fragments generated from $P$. aeruginosa PAO1 genomic DNA (lane 1).
The DNA fragments from F1 and F2 were generated by nebulization at 2.5 and 5 bar pressure, respectively. B. Quality control for cloning: pHERD vector used for library preparation allows white/blue screening for positive inserts. White clones were checked by PCR for the presence of an insert using oligos annealing at both sides of the polylinker sequence. As an example, a check of a randomly selected pool of 25 white colonies is shown (M: molecular weight marker; E. empty vector). It is noteworthy that more than $90 \%$ of clones from F1 (23/25) carried an insert within the expected size range (200-800 bp; average size: $500 \mathrm{bp}$ ), and were used for shotgun cloning. C. SAL recipient PAO1 exconjugants were selected by spotting on PIA plates supplemented with $\mathrm{Cb}$, both in the absence and in the presence of the $\mathrm{P}_{\mathrm{BAD}}$ inducer arabinose. Recipient PAO1 exconjugant spots were inspected for growth defects following $24 \mathrm{~h}$ of incubation at $37^{\circ} \mathrm{C}$. For example: red circle indicates growth impairment only with inducer; yellow circle indicates lethal effects only with inducer; green circle indicates lethal effects both in the presence and absence of the inducer. The identity of the genomic fragments eliciting growth was determined by sequencing the inserts in the corresponding clones of $E$. coli SAL.

Additional file 2: Table S2. Growth-impairing inserts resulting from PAO1 SAL screenings.

Additional file 3: Table S3. PAO1 growth-impairing inserts including multiple loci.

Additional file 4: Table S4. Additional information on a selection of PAO1 "classical" essential genes.

Additional file 5: Table S5. Additional information on novel $P$. aeruginosa candidate essential genes.

Additional file 6: Table S1. List of bacterial strains, plasmids, and oligonucleotides.

\section{Authors' contributions}

$R R, D V, F V$, and GB conceived and designed the experiments. RR, RM, and FV performed the experiments. RR, DV, and GB analyzed the data. DV and GB wrote the paper. All authors read and approved the final manuscript.

\section{Acknowledgments}

The authors are grateful to Andrea Milani and all members of the laboratory for their helpful discussions and technical support. This work was funded by the Italian Cystic Fibrosis Research Foundation (grant FFC\#10/2004) and by the European Commission (grant NABATIVI, EU-FP7-HEALTH-2007-B contract number 223670)

\section{Author details}

'Department of Life Sciences, Università degli Studi di Milano, via Celoria 26, 20133 Milan, Italy. ${ }^{2}$ Alcon Italia S.p.A., viale Richard 1/B, 20143 Milan, Italy.

Received: 2 July 2013 Accepted: 23 January 2014

Published: 5 February 2014

\section{References}

1. Pier GB, Ramphal R: Pseudomonas aeruginosa. In Principles and Practice of Infectious Diseases. Edited by Mandell GL, Bennett JE, Dolin R. Philadelphia, PA: Elsevier Churchill Livingstone; 2005:2587-2615.

2. Wagner VE, Filiatrault MJ, Picardo KF, Iglewski BH: Pseudomonas aeruginosa virulence and pathogenesis issues. In Pseudomonas Genomics and Molecular Biology. Edited by Cornelis P. Norfolk: Caister Academic Press; 2008:129-158.

3. Bonomo RA, Szabo D: Mechanisms of multidrug resistance in Acinetobacter species and Pseudomonas aeruginosa. Clin Infect Dis 2006, 43:S49-S56.

4. Lister PD, Wolter DJ, Hanson ND: Antibacterial-resistant Pseudomonas aeruginosa: clinical impact and complex regulation of chromosomally encoded resistance mechanisms. Clin Microbiol Rev 2009, 22:582-610.

5. Magiorakos AP, Srinivasan A, Carey RB, Carmeli Y, Falagas ME, Giske CG, Harbarth S, Hindler JF, Kahlmeter G, Olsson-Liljequist B, et al: Multidrugresistant, extensively drug-resistant and pandrug-resistant bacteria: an international expert proposal for interim standard definitions for acquired resistance. Clin Microbiol Infect 2012, 18:268-281. 
6. Reznikoff WS, Winterberg KM: Transposon-based strategies for the identification of essential bacterial genes. Methods Mol Biol 2008, 416:13-26.

7. Deng J, Su S, Lin X, Hassett DJ, Lu LJ: A statistical framework for improving genomic annotations of prokaryotic essential genes. PLOS One 2013, 8:e58178.

8. Barquist $L$, Boinett $C J$, Cain AK: Approaches to querying bacterial genomes with transposon-insertion sequencing. RNA Biol 2013, 10:1-9.

9. Liberati NT, Urbach JM, Miyata S, Lee DG, Drenkard E, Wu G, Villanueva J, Wei T, Ausubel FM: An ordered, nonredundant library of Pseudomonas aeruginosa strain PA14 transposon insertion mutants. Proc Natl Acad Sci U S A 2006, 103:2833-2838.

10. Jacobs MA, Alwood A, Thaipisuttikul I, Spencer D, Haugen E, Ernst S, Will O, Kaul R, Raymond C, Levy R, et al: Comprehensive transposon mutant library of Pseudomonas aeruginosa. Proc Natl Acad Sci U S A 2003, 100:14339-14344

11. Judson N, Mekalanos JJ: TnAraOut, a transposon-based approach to identify and characterize essential bacterial genes. Nat Biotechnol 2000, 18:740-745.

12. de Lorenzo $\mathrm{V}$, Timmis KN: Analysis and construction of stable phenotypes in gram-negative bacteria with Tn5- and Tn10-derived minitransposons. Methods Enzymol 1994, 235:386-405.

13. Ji Y, Zhang B, Van SF, Horn, Warren P, Woodnutt G, Burnham MK, Rosenberg M: Identification of critical staphylococcal genes using conditional phenotypes generated by antisense RNA. Science 2001, 293:2266-2269.

14. Forsyth RA, Haselbeck RJ, Ohlsen KL, Yamamoto RT, Xu H, Trawick JD, Wall D, Wang L, Brown-Driver V, Froelich JM, et al: A genome-wide strategy for the identification of essential genes in Staphylococcus aureus. Mol Microbiol 2002, 43:1387-1400.

15. Engdahl HM, Lindell M, Wagner EGH: Introduction of an RNA stability element at the 5 '-end of an antisense RNA cassette increases the inhibition of target RNA translation. Antisense Nucleic Acid Drug Dev 2001, 11:29-40.

16. Wagner EGH, Flardh K: Antisense RNAs everywhere? Trends Genet 2002, 18:223-226.

17. Meng J, Kanzaki G, Meas D, Lam CK, Crummer H, Tain J, Xu HH: A genome-wide inducible phenotypic screen identifies antisense RNA constructs silencing Escherichia coli essential genes. FEMS Microbiol Lett 2012, 329:45-53.

18. Yin D, Ji Y: Genomic analysis using conditional phenotypes generated by antisense RNA. Current Opin Microbiol 2002, 5:330-333.

19. Qiu D, Damron FH, Mima T, Schweizer HP, Yu HD: PBAD-based shuttle vectors for functional analysis of toxic and highly regulated genes in Pseudomonas and Burkholderia spp. and other bacteria. Appl Environ Microbiol 2008, 74:7422-7426.

20. Zhang R, Lin Y: DEG 5.0, a database of essential genes in both prokaryotes and eukaryotes. Nucleic Acids Res 2009, 37:D455-D458.

21. Milani A, Vecchietti D, Rusmini R, Bertoni G: TgpA, a protein with a eukaryotic-like transglutaminase domain, plays a critical role in the viability of Pseudomonas aeruginosa. PLoS One 2012, 7:e50323.

22. Comolli JC, Donohue TJ: Differences in two Pseudomonas aeruginosa cbb3 cytochrome oxidases. Mol Microbiol 2004, 51:1193-1203.

23. Lewenza S, Falsafi RK, Winsor G, Gooderham WJ, McPhee JB, Brinkman FS, Hancock RE: Construction of a mini-Tn5-luxCDABE mutant library in Pseudomonas aeruginosa PAO1: a tool for identifying differentially regulated genes. Genome Res 2005, 15:583-589.

24. Goure J, Pastor A, Faudry E, Chabert J, Dessen A, Attree I: The V antigen of Pseudomonas aeruginosa is required for assembly of the functional PopB/PopD translocation pore in host cell membranes. Infect Immun 2004, 72:4741-4750.

25. Tomalka AG, Stopford CM, Lee PC, Rietsch A: A translocator-specific export signal establishes the translocator-effector secretion hierarchy that is important for type III secretion system function. Mol Microbiol 2012, 86:1464-1481.

26. Tomalka AG, Zmina SE, Stopford CM, Rietsch A: Dimerization of the Pseudomonas aeruginosa translocator chaperone $\mathrm{PcrH}$ is required for stability, not function. J Bacterio/ 2013, 195:4836-4843.

27. Winsor GL, Lam DK, Fleming L, Lo R, Whiteside MD, Yu NY, Hancock RE, Brinkman FS: Pseudomonas genome database: improved comparative analysis and population genomics capability for Pseudomonas genomes. Nucleic Acids Res 2011, 39:D596-D600.
28. Gerdes SY, Scholle MD, Campbell JW, Balazsi G, Ravasz E, Daugherty MD, Somera AL, Kyrpides NC, Anderson I, Gelfand MS, et al: Experimental determination and system level analysis of essential genes in Escherichia coli MG1655. J Bacteriol 2003, 185:5673-5684.

29. Baba T, Ara T, Hasegawa M, Takai Y, Okumura Y, Baba M, Datsenko KA, Tomita M, Wanner BL, Mori H: Construction of Escherichia coli K-12 in-frame, single-gene knockout mutants: the Keio collection. Mol Sys Biol 2006, 2:2006.0008.

30. Whiteside MD, Winsor GL, Laird MR, Brinkman FS: OrtholugeDB: a bacterial and archaeal orthology resource for improved comparative genomic analysis. Nucleic Acids Res 2013, 41:D366-D376.

31. King JD, Kocincova D, Westman EL, Lam JS: Review: Lipopolysaccharide biosynthesis in Pseudomonas aeruginosa. Innate Immun 2009, 15:261-312.

32. Deutsch C, EI YB, de C-LV, Iwata-Reuyl D: Biosynthesis of threonylcarbamoyl adenosine (t6A), a universal tRNA nucleoside. J Biol Chem 2012, 287:13666-13673.

33. Savioz A, Jeenes DJ, Kocher HP, Haas D: Comparison of proC and other housekeeping genes of Pseudomonas aeruginosa with their counterparts in Escherichia coli. Gene 1990, 86:107-111.

34. Essar DW, Eberly L, Hadero A, Crawford IP: Identification and characterization of genes for a second anthranilate synthase in Pseudomonas aeruginosa: interchangeability of the two anthranilate synthases and evolutionary implications. J Bacteriol 1990, 172:884-900.

35. Mahajan-Miklos S, Tan MW, Rahme LG, Ausubel FM: Molecular mechanisms of bacterial virulence elucidated using a Pseudomonas aeruginosa-Caenorhabditis elegans pathogenesis model. Cell 1999, 96:47-56.

doi:10.1186/1471-2180-14-24

Cite this article as: Rusmini et al:: A shotgun antisense approach to the identification of novel essential genes in Pseudomonas aeruginosa. BMC Microbiology 2014 14:24.

\section{Submit your next manuscript to BioMed Central and take full advantage of:}

- Convenient online submission

- Thorough peer review

- No space constraints or color figure charges

- Immediate publication on acceptance

- Inclusion in PubMed, CAS, Scopus and Google Scholar

- Research which is freely available for redistribution 